\title{
0943 USING FRAMING THEORY TO UNITE THE INJURY FIELD AND ADD POWER TO OUR VOICES
}

J Mitchko, W Holmes* Correspondence: Centers for Disease Control and Prevention, National Center for Injury Prevention and Control, 4770 Buford Hwy, NE MS F-63 Atlanta, GA 30341, USA

10.1136/ip.2010.029215.943

Overview CDCs National Center for Injury Prevention and Control sought to identify a new approach to communicating about injury and violence and unite the field of injury around a central message.

Methods CDC used framing theory to develop messages that would have the greatest impact as they present injury in a way that reflects broad and deeply held societal values. Over the last several years, CDC has developed an overarching frame, "we want a society where people can live to their full potential" and frame-based messages on a variety of injury and violence-related topics. The frame and messages were tested with injury representatives, policy makers and the general public using focus groups, in-depth interviews and trainings 


\section{IP Safety 2010 abstracts}

(in person and webinars). Participants identified with the message framing of living to their full potential and helping others to do the same. Based on the findings, "Adding Power to Our Voices," a framing guide (www.cdc.gov/injury/framingguide. html), was developed, giving specific guidance and communication tools to help injury professional connect specific injury issues to the full potential frame so as to create a unified injury message.

Results and Evaluation CDC's injury framing initiative has been well received and has been adopted by CDC staff and partners. A quantitative and qualitative evaluation is currently underway to assess the implementation and use of the injury framing approach. Findings from the evaluation will be presented and will be used to further enhance the injury framing tools and their use. 